\title{
A Dilemma for Globalized Safety
}

\author{
Bin Zhao ${ }^{1}$
}

Received: 10 January 2021 / Accepted: 14 June 2021 /Published online: 24 July 2021

(c) The Author(s) 2021

\begin{abstract}
The safety condition is supposed to be a necessary condition on knowledge which helps to eliminate epistemic luck. It has been argued that the condition should be globalized to a set of propositions rather than the target proposition believed to account for why not all beliefs in necessary truths are safe. A remaining issue is which propositions are relevant when evaluating whether the target belief is safe or not. In the literature, solutions have been proposed to determine the relevance of propositions. This paper examines a case of luckily true belief-thus a case of ignorance - and a case of knowledge. It argues that no solution in the literature offers a correct verdict in either case. Therefore, the strategy to globalize safety remains unsatisfactory.
\end{abstract}

Keywords Epistemic luck $\cdot$ Knowledge $\cdot$ Necessary truths $\cdot$ Safety $\cdot$ Testimony $\cdot$ The basis of beliefs $\cdot$ The generality problem

\section{Introduction}

The idea behind the safety condition is that in order to know one's belief could not easily have been false. In short, the belief should be true not only in the actual case but also in similar cases (where one forms it in the same way as in the actual case). A belief that satisfies the safety condition is insusceptible to knowledge-precluding epistemic luck. It thus counts as knowledge unless it exhibits some non-modal shortcomings that would deprive it of the status of knowledge.

When evaluating whether a belief is safe or not, it was thought that it was enough to examine beliefs in the same proposition in similar cases (Sosa, 1999a, b). However, problems incurred by necessary truths and modally robust contingent truths cast doubt on that idea because a belief in these truths is trivially safe, though such a belief could still be true as a matter of luck. It was then suggested that, when

Bin Zhao

binz8@uci.edu

1 Department of Philosophy, University of California at Irvine, 85 Humanities Instructional Building, Irvine, CA 92697-4555, USA 
evaluating whether the target belief is safe or not, we should also take beliefs in some other relevant propositions in similar cases into consideration. What results from this suggestion is a globalized version of the safety condition (Ball, 2016; Blome-Tillmann, 2017; Grundmann, 2020; Hirvelä, 2019; Manley, 2007; Pritchard, 2009, 2012a, 2013, 2016; Williamson, 2000, 2009). But which propositions are relevant when evaluating whether a belief is safe?

In this paper, I shall construct a dilemma for the globalized version of the safety condition. The dilemma is based on a case of luckily true belief-thus a case of ignorance - and a case of knowledge. It is argued that no solution to the problem of the relevance of propositions offers a correct verdict in either case. Therefore, they constitute a dilemma for the safety theorists.

\section{Safety Globalized}

Consider a scenario where one looks at a reliable clock in normal lighting condition and thus forms a true belief that it is now 12:00. Since the clock is reliable and the lighting condition is normal, the belief counts as knowledge. Consider another scenario where one looks at a clock that stops $12 \mathrm{~h}$ earlier in normal lighting condition and thus forms a true belief that it is now 12:00. The belief is true as a matter of luck and does not count as knowledge. After all, it is true because the dose of bad luck that the clock is stopped is canceled out by the good luck that the clock stops $12 \mathrm{~h}$ ago.

Why is it the case that one knows the correct time in the first scenario but not in the second scenario though in both scenarios one has a true belief about the time? The safety account of knowledge offers a simple answer to this question. According to this account, $S$ knows that $p$ only if $S$ 's belief that $p$ is safe, that is, only if $S$ could not easily have falsely believed $p$. To put it formally,

SAFETY: $S$ 's belief that $p$, formed on basis $B$, is safe, if and only if, in all nearby possible worlds where $S$ forms a belief that $p$ on basis $B, p$ is true. ${ }^{1}$

This makes us consider whether $p$ is true in nearby possible worlds where $S$ believes that $p$. If $p$ is false in some of these possible worlds, then $S$ 's belief in $p$ is not safe, and $S$ does not know that $p$. If $p$ is true in all these possible worlds, then $S$ 's belief in $p$ is safe, and $S$ knows that $p$ unless it exhibits some non-modal shortcomings that would deprive it of the status of knowledge. One knows the correct time in the first scenario because his belief is safe. In all nearby possible worlds where he believes that it is now 12:00 via the clock, it is 12:00. One does not know the correct

\footnotetext{
1 The safety condition is sometimes relativized to belief-forming methods rather than the basis of beliefs. See Blome-Tillmann (2020) for cases where the two versions of the safety condition come apart. In this paper, I shall not delve into the issue of how to relativize the condition. Proponents of the safety condition on knowledge include Ball (2016), Beddor and Pavese (2020), Dutant (2010, 2016), Grundmann (2020), Hirvelä (2019), Luper (2003, 2006a, b), Luper-Foy (1984), Manley (2007), Peet and Pitcovski (2018), Pritchard (2002, 2005, 2007, 2008a, b, 2009, 2012a, b, 2013, 2015, 2016, 2018), Sainsbury (1997), Sosa (1999a, b), and Williamson (2000).
} 
time in the second scenario because his belief is unsafe. There are some nearby possible worlds where he looks at the clock $1 \mathrm{~min}$ earlier and believes that it is now 12:00 via the clock, while the time is 11:59.

In a word, the safety condition is supposed to be a necessary condition on knowledge that helps to eliminate epistemic luck. In virtue of this, the safety account of knowledge does an excellent job to handle cases where the subject's belief is true as a matter of luck. However, there are still some cases where the subject's belief satisfies the safety condition, whereas the belief is luckily true. To illustrate, consider the following scenario,

MATHEMA: "Mathema uses a calculator to find out the sum of $12 \times 13$. As a result, he forms a true belief that $12 \times 13=156$. Unbeknownst to Mathema, however, his calculator is in fact broken and generating 'answers' randomly." (Pritchard, 2012a, p. 256)

Since $12 \times 13=156$ is a necessary truth, it is true in all possible worlds. Therefore, it is true in all nearby possible worlds where Mathema believes it. This makes his belief trivially safe according to SAFETY. However, the belief is luckily true and thus does not count as knowledge. This causes a problem for SAFETY which is supposed to be a necessary condition on knowledge that helps to eliminate knowledgeprecluding luck. $^{2}$

Though Mathema could not easily have formed a false belief in the target proposition, he could easily have formed a false belief in a different proposition. Since the calculator is generating "answers" randomly, he may as well believe something like $12 \times 13=157$ by using the calculator. The insight is that, when evaluating whether a belief is safe or not, we should also examine beliefs in some other relevant propositions in addition to the target belief in similar cases.

As Duncan Pritchard writes, "what we are interested in is rather how the agent forms her beliefs in similar circumstances and in response to the same stimuli. These beliefs may be beliefs that $p$, but equally they may be beliefs in distinct propositions" (Pritchard, 2012a, pp. 256-257). If we globalize SAFETY to a set of relevant propositions rather than the target proposition, then Mathema turns out to be unsafe which accounts for why it is true as a matter of luck and thus does not count as knowledge. This seems to be a satisfactory solution to the problem incurred by beliefs in necessary truths. The remaining issue is how to determine which propositions are relevant when evaluating whether a belief is safe. After all, there must be some constraint on which propositions are relevant. Otherwise, a belief can hardly be safe as the subject always could easily have formed a false belief in some proposition.

\footnotetext{
${ }^{2}$ For similar arguments, see Becker (2007), Blome-Tillmann (2017), Collin (2018), Melchior (2017, 2021), Miščević (2007), and Roland and Cogburn (2011). Bernecker (2011), Broncano-Berrocal (2019), Freitag (2014), Greco (2016), Hiller and Neta (2007), Hirvelä (2019), Kripke (2011), Paterson (2020), and Stone (2013) also argue that in addition to necessary truths, modally robust contingent truths which are true in all nearby possible worlds cause the same problem for SAFETY.
} 
The safety theorists such as Duncan Pritchard and Timothy Williamson have proposed solutions to how the set of relevant propositions is constrained. According to Pritchard's solution, the set of relevant propositions is constrained by the basis of the belief. We should only consider beliefs that are formed on the same basis, while beliefs formed on a different basis are irrelevant when evaluating whether the target belief is safe. ${ }^{3}$ To put it formally,

SAFETY $^{P}: S$ 's belief that $p$, formed on basis $B$, is safe, if and only if, in all nearby possible worlds where $S$ forms a belief on basis $B, S$ 's belief is true. (Pritchard, 2009, 2012a, 2013, 2016) ${ }^{4}$

Williamson's solution is somewhat vague as it draws on the notion of "closeness." As he claims, "if at time $t$ on basis $b$ one knows $p$, and at a time $t^{*}$ close enough to $t$ on a basis $\mathrm{b}^{*}$ close enough to $\mathrm{b}$ one believes a proposition $p^{*}$ close enough to $p$, then $p^{*}$ should be true" (Williamson, 2000, p. 102). That is to say, a belief in a proposition that is formed on a different basis can also be relevant as long as the proposition is close to the target proposition and the basis is also close to the actual basis. ${ }^{5}$ To put it formally,

SAFETY $^{W}: S$ 's belief that $p$, formed on basis $B$, is safe, if and only if, in all nearby possible worlds where $S$ forms a belief in a proposition close to $p$ on a basis close to $B, S$ 's belief is true. (Williamson, 2000, 2009)

The problem with both solutions is that they largely rely on the individuation of the basis of beliefs. If the basis is individuated in a fine-grained way, then fewer propositions would be relevant which might make the safety condition fail to eliminate epistemic luck. If the basis is individuated in a coarse-grained way, then more propositions would be relevant which would make it very difficult to know

\footnotetext{
3 This is motivated by his anti-luck epistemology according to which the safety condition is the anti-luck condition on knowledge. As he argues, when evaluating whether an event is lucky, we should consider nearby possible worlds where the relevant initial conditions for that event are the same as in the actual world. When the event is the formation of a belief, the relevant initial conditions turn out to be the basis of that belief. See Pritchard (2005, 2007, 2012a, b).

4 Blome-Tillmann (2017) also defends a version of globalized safety, which is not significantly different from Pritchard's (2012a, b) version, to account for why not all beliefs in necessary truths count as knowledge.

5 Hirvelä (2019) argues that we should only consider beliefs that are formed on the same virtuous method and propositions which belong to the same subject matter of inquiry as the target proposition. To put it formally,

SAFETY ${ }^{H}: S$ 's belief that $p$, which belongs to her subject matter of inquiry $Q$, formed on a virtuous method $V$, is safe, if and only if, in all nearby possible worlds where $S$ forms a belief in a proposition that belongs to $Q$ via the virtuous method $V, S$ 's belief is true. (Hirvelä, 2019, p. 1184).

SAFETY ${ }^{H}$ also handles MATHEMA nicely. Though Sam could not easily have formed a false belief that $12 \times 13=156$, he could easily have formed a false belief that $12 \times 13=157$ on the same virtuous method as that in the actual case. In addition, the true proposition and the false propositions belong to the same subject matter of inquiry that "what is the result of 12 times 13 ?" Therefore, his target belief is unsafe and thus does not count as knowledge.
} 
something. How do we determine which individuation is the correct one ${ }^{6}$ We seem to have a version of the generality problem here.

In the literature, counterexamples to $\mathrm{SAFETY}^{P}$ or $\mathrm{SAFETY}^{W}$ have been constructed to show that there are scenarios where one knows something despite falsely believing a proposition on the same basis or a close proposition on a close basis in a similar case. For instance,

SCOREBOARD: Mia walks into The Penalty Box, a well-known soccer bar and asks the first customer that comes along about the result of the FIFA World Cup game that ended an hour ago. The customer addressed by Mia knows that the game ended in a tie and informs her accordingly. Suppose the customer could have easily responded to Mia's question by giving her the final score, say 2-2 instead of telling her that the game ended in a tie. Further, suppose all the soccer fans in the bar are reliable informants about which team won, lost or tied but, unwittingly, they are frequently wrong about the scores of games." (Bernecker, 2020, p. 5108) ${ }^{7}$

Intuitively, Mia knows that the game ended in a tie via testimony. Given that the customer could easily have responded to her question by giving her the final score and the fact that all the soccer fans in the bar are not reliable informants about the scores of games, Mia could easily have falsely believed that that the score was 1-1. Therefore, Mia knows that the game ended in a tie though she could easily have formed a false belief in a proposition, i.e., the score was 1-1, close to the target proposition on her actual basis of "the testimony of a customer at a well-known soccer bar who is reasonably thought to be knowledgeable" (Bernecker, 2020, p. 5109). In a word, SCOREBOARD is supposed to be a counterexample to both SAFETY $^{P}$ and SAFETY ${ }^{W}$.

Whether the counterexamples work depends on the individuation of the basis of beliefs as well as an account of the closeness of propositions. Whenever the critics claim that the basis in the similar case is the same as/close to the basis in the actual case or claim that the proposition in the similar case is close to the target proposition, the safety theorists might argue that the basis should be individuated in another way or argue that the proposition under discussion is not close to the target proposition.

For instance, in SCOREBOARD, the safety theorists might argue that the basis should be individuated in a more fine-grained way. After all, the testimony of the customer is not enough for believing that the game ended in a tie because this does not specify what he testifies. If what he testifies is included in the basis, then the basis will be individuated as the testimony that the game ended in a tie from a customer at a well-known soccer bar who is reasonably thought to be knowledgeable.

\footnotetext{
${ }^{6}$ For discussions of the individuation of the basis of beliefs, see Alfano (2009), Becker (2012), Bernecker (2020), Black and Murphy (2007), Bogardus and Marxen (2014), Broncano-Berrocal (2014), and Hirvelä (2019).

7 For a similar scenario, see Zhao (2019).
} 
In that case, Mia could not easily have formed a false belief on her actual basis and thus SCOREBOARD fails as a counterexample to SAFETY ${ }^{P}$.

The safety theorists might as well deny that the proposition that the score was $1-1$ is close to the target proposition that the game ended in a tie. For example, they might argue that a proposition is close to another proposition only if they are always answers to the same question. This explains why the proposition that the score was $1-1$ is not close to the target proposition that the game ended in a tie, viz. the former but not the latter is an answer to the question that "what is the exact final score?" that is the case, then SCOREBOARD fails as a counterexample to SAFETY ${ }^{W}$.

Thus, the debate between the safety theorists and their critics would be diverted to a debate about the individuation of the basis of beliefs and the closeness of propositions. However, given that a ready-to-hand solution to the generality problem and a well-accepted account of the closeness of propositions are not available to us, it is unclear whether the debate between them is fruitful.

\section{A Dilemma for Globalized Safety}

Nonetheless, I'd like to raise an objection to the globalized version of the safety condition. Instead of proposing a solution to the generality problem or an account of the closeness of propositions, my objection is based on a case of luckily true belief - thus a case of ignorance - and a case of knowledge. The idea is that, if the safety theorists opt for a solution to the generality problem/account of the closeness of propositions that accommodates the case of luckily true belief, then they fail to offer the correct verdict in the case of knowledge. If they opt for another solution to the generality problem/account of the closeness of propositions that accommodates the case of knowledge, then they fail to offer the correct verdict in the case of luckily true belief. Therefore, for any solution to the generality problem/account of the closeness of propositions, it is not able to offer correct verdicts in both cases. That is to say, the cases constitute a dilemma for the safety theorists.

To illustrate the objection, consider the case of luckily true belief first,

ROGER: "Consider Roger, who believes $~ B I V 6$ [which is the negation of the proposition that MI6 secretly keeps a collection of envatted brains, artificially stimulated to produce the experiences of normal embodied human beings], but for slightly unorthodox reasons. ... [H] is convinced that MI6 doesn't engage in these activities, the reason is that he has a friend [Novak] who tells him that he works for MI6 and is always prepared to answer his questions about this service. . . . Suppose that [Novak] is a reliable informant on all topics except on the question whether MI6 keeps envatted brains. On this question, [Novak] believes falsely that MI6 does keep envatted brains, but for some reason he is

\footnotetext{
${ }^{8}$ In contrast, according to this notion of the closeness of propositions, the proposition that $12 \times 13=157$ is close to the proposition that $12 \times 13=156$, viz. they are always answers to the question that "what is the result of 12 times 13 ?" This helps to deliver the correct verdict in MATHEMA.
} 
strongly committed to ensuring that Roger doesn't find out, so he tells him, insincerely, but, as it happens, truly, that MI6 doesn't keep envatted brains, and this is so in all nearby worlds, as well as in at least some of the nearest worlds in which BIV6 is true. . . It is on these grounds that Roger believes $~ B I V 6 . "$ (Zalabardo, 2017, pp. 8-10)

As we remember, the subject in the scenario of the stopped clock forms a true belief about the time as a matter of luck. After all, his belief is true because the dose of bad luck he encounters that the clock is stopped is canceled out by the good luck that the clock stops $12 \mathrm{~h}$ ago. Similarly, Roger also encounters a dose of bad luck that his friend Novak attempts to mislead him, and that dose of bad luck is canceled out by the good luck that Novak's own belief about MI6 is wrong. In the end, Roger forms a true belief about MI6 as a matter of luck. Since the belief is luckily true, it does not count as knowledge. $9,10,11$

Nonetheless, Roger's belief that $\sim B I V 6$ seems to be safe because he could not easily have formed a false belief on Novak's testimony. First, his belief that $\sim$ BIV6 is true in all nearby possible worlds since it is technically impossible to artificially stimulate envatted brains to produce the experiences of normal embodied human beings. Second, if he forms a different belief on Novak's testimony, then that belief is also true in all nearby possible worlds because Novak is a reliable informant on all topics except on the question whether MI6 keeps envatted brains. Thus, we seem to have a luckily true belief which does not count as knowledge but is globally safe.

The safety theorists need to argue that Roger could easily have formed a false belief which, in turn, renders his belief that BIV6 unsafe. Since Roger's belief that $\sim B I V 6$ is guaranteed to be true in all nearby possible worlds and it is also stipulated that Novak is a reliable informant on all topics except on the question whether MI6 keeps envatted brains, this seems to be an impossible mission for them.

\footnotetext{
9 This is compatible with its not satisfying some other necessary conditions on knowledge. The idea here is that its being true as a matter of luck suffices for its not being knowledge.

10 Melchior (2021) constructs a similar case in which the subject's belief is globally safe though it does not count as knowledge. However, as I have argued, the safety theorists might opt for some solution to the generality problem/account of the closeness of propositions to accommodate the case.

11 One might claim that Roger's belief that $\sim B I V 6$ is not luckily true because the belief is modally stable. However, unless one has already assumed a modal account of luck, the intuition that the belief is luckily true is quite robust. After all, ROGER, like other Gettier cases involving knowledge-precluding epistemic luck, is a case where a dose of bad luck is canceled out by a dose of good luck. The structural similarity could be further explicated by the following case:

TOM: Tom and Jerry are colleagues working in the same company. They usually have lunch together. One day, Tom asks Jerry if Tomi Sushi Buffet is open. Jerry checks Google Maps and finds that the restaurant is open. However, Jerry wants to have lunch in another restaurant because he is not a big fan of sushi. Jerry thus tells Tom insincerely that Tomi Sushi Buffet is closed. What is unbeknownst to Jerry is that Google Maps has not been updated for a while and it always shows that the restaurant is open. As a result, Tom forms a true belief that Tomi Sushi Buffet is closed though that very belief is true as a matter of luck.

TOM is structurally similar to ROGER as it also involves a dose of bad luck, i.e., Jerry attempts to mislead Tom, that is canceled out by a dose of good luck, i.e., Tom's own belief about Tomi Sushi Buffet is wrong. If TOM involves knowledge-precluding epistemic luck, then ROGER should involve that sort of luck as well. In sum, it is not a starting point to deny that Roger's belief that $\sim B I V 6$ is luckily true.
} 
The good news is that Roger could easily have falsely believed that Novak believes/knows that BIV6. After all, if Novak was asked whether he believes that $\sim B I V 6$, then he would misleadingly answer "yes" to make sure that Roger does not find out the relevant fact. The safety theorists might want to argue that, when evaluating whether Roger's target belief is safe or not, we should also take his belief that Novak believes/knows that BIV6 in similar cases into consideration. For this strategy to work, the advocates of SAFETY $^{P}$ still need to individuate the basis of the belief in a coarse-grained way, i.e., Novak's testimony, such that Roger's belief that Novak believes/knows that BIV6 is formed on the same basis as in the actual case, while the advocates of SAFETY ${ }^{W}$ need to argue that the proposition that Novak believes/knows that $\sim$ BIV6 is close to $\sim$ BIV6.

Because the payoff is great, they may well make this move. This move, however, is not without its cost. As I will argue shortly, if the safety theorists make this move to accommodate cases of luckily true belief such as ROGER, then they will offer incorrect verdicts in some cases of knowledge. The conclusion is that they are not able to offer correct verdicts in all cases. To illustrate, consider the following scenario,

CREATIONIST TEACHER: Stella is a devoutly Christian fourth-grade teacher, and her religious beliefs are grounded in a deep faith that she has had since she was a very young child. Part of this faith includes a belief in the truth of creationism and, accordingly, a belief in the falsity of evolutionary theory. Despite this, she fully recognizes that there is an overwhelming amount of scientific evidence against both of these beliefs. Indeed, she readily admits that she is not basing her own commitment to creationism on evidence at all but, rather, on the personal faith that she has in an all-powerful Creator. Because of this, Stella does not think that religion is something that she should impose on those around her, and this is especially true with respect to her fourth-grade students. Instead, she regards her duty as a teacher to involve presenting material that is best supported by the available evidence, which clearly includes the truth of evolutionary theory. In addition, Stella is not allowed to talk about her religious beliefs openly. What's worse, there is a school obligation that forces her to lie to the students that she believes what she teaches wholeheartedly. As a result, after consulting reliable sources in the library and developing reliable lecture notes, Stella asserts to her students, "Modern-day Homo sapiens evolved from Homo erectus," while presenting her biology lesson today. Though Stella herself neither believes nor knows this proposition, she never shares her own personal faith-based views with her students, and so they form the corresponding true belief solely on the basis of her reliable testimony.

This is a modified version of the scenario which Jennifer Lackey (2008) constructed as a counterexample for the transmission theory of testimonial knowledge according to which testimonial knowledge can be acquired only by being transmitted from the testifier to the recipient of the testimony. 
Though there is disagreement on whether Lackey successfully refutes the theory, ${ }^{12}$ it is widely accepted that the students, in the scenario, presumably acquire the knowledge that Modern-day Homo sapiens evolved from Homo erectus because the information has been reliably conveyed to them though Stella does not have that knowledge as she does not believe that at all (Carter \& Nickel, 2014; Faulkner, 2011; Graham, 2006). Given that the students know that Modern-day Homo sapiens evolved from Homo erectus, the safety theorists should be able to offer the verdict that the students' belief is safe.

Is the students' belief safe? That depends on which propositions are relevant when evaluating whether it is safe. Indeed, they could not easily have formed a false belief in the target proposition given that the information was reliably conveyed to them and the very proposition is true in all nearby possible worlds. However, they could easily have falsely believed that Stella believes/knows that Modern-day Homo sapiens evolved from Homo erectus. After all, if Stella was asked whether she believes what she teaches, she would misleadingly answer "yes" in order to follow the school obligation. For the students' belief to be safe, the proposition should not be rendered relevant.

ROGER is a case of luckily true belief, and thus a case of ignorance. CREATIONIST TEACHER is a case of knowledge. Yet there are many similarities between them. Both are scenarios where the subject forms a true belief in some proposition on the basis of testimony. Given the modal profile of the target proposition, the belief is also guaranteed to be true in all nearby possible worlds. However, the testifier actually believes in the negation of the target proposition. In addition, in both scenarios, the subject could easily have falsely believed that the testifier believes/knows the target proposition. ${ }^{13}$

It has been shown that for Roger's belief to be unsafe, which explains why it is luckily true and thus does not count as knowledge, the advocates of SAFETY ${ }^{P}$ need to argue that Roger's belief that Novak believes/knows that BIV6 in

\footnotetext{
12 After all, there is still someone in the chain of testifiers, e.g., the person from whom Stella acquired the testimony, who knows that Modern-day Homo sapiens evolved from Homo erectus.

Another potential dissimilarity is that Stella, but not Novak, is representing an institution and hence can properly be taken to act under a role. Therefore, the assumption that Stella believes/knows what she says is not legitimate, since she is merely reporting what the scientific view on the matter is. In virtue of this dissimilarity, it could be argued that the proposition that the testifier believes/knows the target proposition is relevant in ROGER but not in CREATIONIST TEACHER. The problem is that Novak works for MI6 and is a reliable informant on a majority of topics. It is easy to fix the case in such a way that Novak is also representing an institution and hence can properly be taken to act under a role. Thus, the potential dissimilarity disappears.

13 It might be pointed out that there is some dissimilarity between them: Roger believes that $\sim$ BIV6 because he believes that Novak believes/knows that BIV6. If Roger doesn't believe this about Novak, then he wouldn't believe $\sim$ BIV6; though the students also falsely believe that Stella believes/knows that Modern-day Homo sapiens evolved from Homo erectus, that is not the reason why they believe that Modern-day Homo sapiens evolved from Homo erectus. They hold that belief because they correctly believe that the curriculum is a reliable indicator of the truth. Nonetheless, we can fix the case in such a way that the students are instructed by their parents to believe everything taught by Stella because "Stella knows everything (or, at least, everything she teaches)." This ensures that there is not such a dissimilarity between ROGER and CREATIONIST TEACHER.
} 
similar cases is formed on the same basis as in the actual case, while the advocates of SAFETY ${ }^{W}$ need to argue that the proposition that Novak believes/knows that $\sim$ BIV6 is close to $\sim$ BIV6.

However, if the basis of the belief is individuated in such a way, i.e., Novak's testimony, that Roger's belief that Novak believes/knows that BIV6 in similar cases is formed on the same basis as that in the actual case, then we should also think that the students' belief that Stella believes/knows that Modern-day Homo sapiens evolved from Homo erectus in similar cases is formed on the same basis as that in the actual case, i.e., Stella's testimony. Similarly, if the proposition that Novak believes/knows that $\sim$ BIV6 is close to the proposition that $\sim B I V 6$, then the proposition that Stella believes/knows that Modern-day Homo sapiens evolved from Homo erectus should also be close to the proposition that Modern-day Homo sapiens evolved from Homo erectus. Thus, the proposition that Stella believes/knows that Modern-day Homo sapiens evolved from Homo erectus should be relevant when evaluating whether the students' target belief is safe or not. In that case, given that they could easily have falsely believed that Stella believes/knows that Modern-day Homo sapiens evolved from Homo erectus, the students' target belief is unsafe and thus does not count as knowledge which contradicts our intuition concerning CREATIONIST TEACHER.

Likewise, if the safety theorists argue that the proposition that Stella believes/ knows that Modern-day Homo sapiens evolved from Homo erectus is irrelevant when evaluating whether the students' belief is safe or not, ${ }^{14}$ then, by similar reasoning, the proposition that Novak believes/knows that BIV6 should also be irrelevant when evaluating whether Roger's belief is safe or not. In that case, though Roger could easily have falsely believed that Novak believes/knows that BIV6, his target belief is safe and thus not luckily true, which contradicts our intuition concerning ROGER. Therefore, the safety theorists are unable to claim that Roger's belief is unsafe, whereas the students' belief is safe. ${ }^{15}$

\footnotetext{
14 For this to work, the advocates of $\mathrm{SAFE}^{P}$ might appeal to a fine-grained individuation of the basis of the belief, i.e., the speaker's testimony that $p$; while the advocates of $\mathrm{SAFE}^{W}$ need to argue that the proposition that the speaker believes that $p$ is not close to the proposition that $p$.

15 One might argue that Novak is trying to deceive Roger as he has a bad intention to make sure that Novak does not find out the relevant fact; while Stella is not trying to deceive the student as she is teaching in accordance with our best scientific knowledge. If the proposition that the testifier is not trying to deceive me is relevant when evaluating whether Roger/the students' target belief is safe or not, then it turns out that Roger's belief is unsafe, while the students' belief is safe.

Here is my response: the notion of "deception" is ambiguous here. It could either mean that "intentionally causing the hearer to form a belief that the testifier takes to be true" or mean that "intentionally causing the hearer to form a false belief." According to the first interpretation, both Novak and Stella are trying to deceive because they all take the proposition they testify to be false. According to the second interpretation, neither Novak nor Stella is trying to deceive because the hearer ends up with a true belief in both cases. Therefore, it is not the case that Novak is trying to deceive Roger; while Stella is not trying to deceive the student. Thus, no matter whether the proposition that the testifier is not trying to deceive $m e$ is relevant to the safety of the target belief, the above strategy does not yield a welcome result for the safety theorists. See Baron (1988) and Mahon (2016) for more discussion on the conditions of deception. I thank an anonymous referee for helping me clarify the issue here.
} 


\section{Conclusion}

To summarize, despite the similarities between ROGER and CREATIONIST, there is a significant difference between them. While ROGER is a case of luckily true belief, thus a case of ignorance, CREATIONIST is a case of knowledge. To account for why Roger's belief is unsafe and thus does not count as knowledge, the proposition that Novak believes/knows that BIV6 is rendered relevant when evaluating whether Roger's belief is safe. In that case, the proposition that Stella believes/knows that Modern-day Homo sapiens evolved from Homo erectus should also be relevant when evaluating whether the students' target belief is safe. Thus, we end up with the conclusion that CREATIONIST TEACHER, like ROGER, is a case of luckily true belief, and thus a case of ignorance. To accommodate the intuition that CREATIONIST TEACHER is a knowledge case, the safety theorists should push back to argue that the proposition that Stella believes/knows that Modern-day Homo sapiens evolved from Homo erectus is irrelevant when evaluating whether the students' belief is safe. However, in that case, we end up with the conclusion that ROGER, like CREATIONIST TEACHER, is a case of knowledge or (at least) a case of nonluckily true belief.

To give correct verdicts in both cases, the safety theorists might rework an account of individuation of the basis of beliefs or an account of the closeness of propositions as explained above. Yet this must be principled and it must avoid the above dilemma. Till then, the strategy to globalize safety, which was motivated to account for why beliefs in necessary truths could be true as a matter of luck, remains unsatisfactory. $^{16}$

Open Access This article is licensed under a Creative Commons Attribution 4.0 International License, which permits use, sharing, adaptation, distribution and reproduction in any medium or format, as long as you give appropriate credit to the original author(s) and the source, provide a link to the Creative Commons licence, and indicate if changes were made. The images or other third party material in this article are included in the article's Creative Commons licence, unless indicated otherwise in a credit line to the material. If material is not included in the article's Creative Commons licence and your intended use is not permitted by statutory regulation or exceeds the permitted use, you will need to obtain permission directly from the copyright holder. To view a copy of this licence, visit http://creativecommons.org/licen ses/by/4.0/.

\section{References}

Alfano, M. (2009). Sensitivity theory and the individuation of belief-formation methods. Erkenntnis, 70(2), $271-281$.

Ball, B. (2016). Knowledge, safety, and questions. Filosofia Unisinos, 17(1), 58-62.

Baron, M. (1988). What is wrong with self-deception? In B. P. McLaughlin \& A. O. Rorty (Eds.), Perspectives on self-deception (pp. 431-449). University of California Press.

Becker, K. (2007). Epistemology Modalized. Routledge.

Becker, K. (2012). Methods and how to individuate them. In K. Becker \& T. Black (Eds.), The Sensitivity Principle in Epistemology (pp. 81-97). Cambridge University Press.

\footnotetext{
${ }^{16}$ I would like to thank Sven Bernecker, Josh Dolin, Duncan Pritchard, and two anonymous referees for helpful comments and suggestions.
} 
Beddor, B., \& Pavese, C. (2020). Modal virtue epistemology. Philosophy and Phenomenological Research, 101(1), 61-79.

Bernecker, S. (2011). Keeping track of the Gettier problem. Pacific Philosophical Quarterly, 92(2), 127-152.

Bernecker, S. (2020). Against global method safety. Synthese, 197(12), 5101-5116.

Black, T., \& Murphy, P. (2007). In defense of sensitivity. Synthese, 154(1), 53-71.

Blome-Tillmann, M. (2017). Sensitivity actually. Philosophy and Phenomenological Research, 94(3), 606-625.

Blome-Tillmann, M. (2020). Non-reductive safety. Belgrade Philosophical Annual, 33, 25-38.

Bogardus, T., \& Marxen, C. (2014). Yes, safety is in danger. Philosophia, 2, 1-14.

Broncano-Berrocal, F. (2014). Is safety in danger? Philosophia, 42(1), 1-19.

Broncano-Berrocal, F. (2019). Knowledge, safety, and Gettierized lottery cases: Why mere statistical evidence is not a (safe) source of knowledge. Philosophical Issues, 29(1), 37-52.

Carter, J. A., \& Nickel, P. J. (2014). On testimony and transmission. Episteme, 11(2), 145-155.

Collin, J. (2018). Towards an account of epistemic luck for necessary truths. Acta Analytica, 33(4), 483-504.

Dutant, J. (2010). Two notions of safety. Swiss Philosophical Preprints, 87, 1-19.

Dutant, J. (2016). How to be an infallibilist. Philosophical Issues, 26(1), 148-171.

Faulkner, P. (2011). Knowledge on trust. Oxford University Press.

Freitag, W. (2014). Safety, Sensitivity And 'Distant' epistemic luck. Theoria, 80(1), 44-61.

Graham, P. J. (2006). Can testimony generate knowledge? Philosophica, 78, 105-127.

Greco, J. (2016). Knowledge, virtue, and safety. In M. Ángel \& F. Vargas (Eds.), Performance epistemology: Foundations and applications (pp. 51-61). Oxford University Press.

Grundmann, T. (2020). Saving safety from counterexamples. Synthese, 197, 5161-5185.

Hiller, A., \& Neta, R. (2007). Safety and epistemic luck. Synthese, 158, 303-313.

Hirvelä, J. (2019). Global safety: How to deal with necessary truths. Synthese, 196(3), 1167-1186.

Kripke, S. (2011). Nozick on knowledge. Philosophical Troubles: Collected Papers (Vol. 1, pp. 162-224). Oxford University Press.

Lackey, J. (2008). Learning from words: Testimony as a source of knowledge. Oxford University Press.

Luper, S. (2003). Indiscernability skepticism. In S. Luper (Ed.), The skeptics: Contemporary essays (ashgate epistemology and mind series) (pp. 183-202). Ashgate Publishing.

Luper, S. (2006a). Dretske on knowledge closure. Australasian Journal of Philosophy, 84(3), 379-394.

Luper, S. (2006b). Restorative rigging and the safe indication account. Synthese, 153(1), 161-170.

Luper-Foy, S. (1984). The epistemic predicament: Knowledge, Nozickian tracking, and scepticism. Australasian Journal of Philosophy, 62(1), 26-49.

Mahon, J. E. (2016). The definition of lying and deception. In Edward N. Zalta (ed.), The Stanford Encyclopedia of Philosophy. https://plato.stanford.edu/archives/win2016/entries/lying-definition/.

Manley, D. (2007). Safety, content, apriority, self-knowledge. Journal of Philosophy, 104(8), 403-423.

Melchior, G. (2017). Epistemic luck and logical necessities: Armchair luck revisited. In B. Borstner \& S. Gartner (Eds.), Thought experiments between nature and society: A Festschrift for Nenad Miščević (pp. 137-150). Cambridge Scholars Publishing.

Melchior, G. (2021). Sensitivity, safety, and impossible worlds. Philosophical Studies. https://doi.org/10. 1007/s11098-020-01453-8.

Miščević, N. (2007). Armchair luck: Apriority, intellection and epistemic luck. Acta Analytica, 22(1), 48-73.

Paterson, N. J. (2020). Safety and necessity. Erkenntnis. https://doi.org/10.1007/s10670-020-00231-6.

Peet, A., \& Pitcovski, E. (2018). Normal knowledge: Toward an explanation-based theory of knowledge. Journal of Philosophy, 115(3), 141-157.

Pritchard, D. (2002). Resurrecting the Moorean response to the sceptic. International Journal of Philosophical Studies, 10, 283-307.

Pritchard, D. (2005). Epistemic luck. Oxford University Press.

Pritchard, D. (2007). Anti-luck epistemology. Synthese, 158, 277-298.

Pritchard, D. (2008a). Knowledge, luck, and lotteries. In V. F. Hendricks \& D. Pritchard (Eds.), New waves in epistemology (pp. 28-51). Palgrave Macmillan.

Pritchard, D. (2008b). Sensitivity, safety, and anti-luck epistemology. In J. Greco (Ed.), The Oxford handbook of scepticism (pp. 437-455). Oxford University Press.

Pritchard, D. (2009). Safety-based epistemology: Whither now? Journal of Philosophical Research, 34, $33-45$.

Pritchard, D. (2012a). Anti-luck virtue epistemology. Journal of Philosophy, 109(3), 247-279.

Pritchard, D. (2012b). In defence of modest anti-luck epistemology. In T. Black \& K. Becker (Eds.), The sensitivity principle in epistemology (pp. 173-192). Cambridge University Press. 
Pritchard, D. (2013). Knowledge cannot be lucky. In M. Steup, J. Turri, \& E. Sosa (Eds.), Contemporary Debates in Epistemology (2nd ed., pp. 152-164). Blackwell.

Pritchard, D. (2015). Anti-luck epistemology and the Gettier problem. Philosophical Studies, 172, 93-111.

Pritchard, D. (2016). Epistemology (2nd ed.). Palgrave Macmillan.

Pritchard, D. (2017). Knowledge, luck and virtue: Resolving the Gettier problem. In R. Borges, C. de Almeida, \& P. Klein (Eds.), Explaining knowledge: New essays on the Gettier problem (pp. 57-73). Oxford University Press.

Pritchard, D. (2018). The Gettier problem and epistemic luck. In S. Hetherington (Ed.), The Gettier Problem (pp. 96-107). Cambridge University Press.

Roland, J., \& Cogburn, J. (2011). Anti-luck epistemologies and necessary truths. Philosophia, 39(3), 547-561.

Sainsbury, R. M. (1997). Easy possibilities. Philosophy and Phenomenological Research, 57(4), 907-919.

Sosa, E. (1999a). How must knowledge be modally related to what is known? Philosophical Topics, $26(1$ \& 2), 373-384.

Sosa, E. (1999b). How to defeat opposition to Moore. Philosophical Perspectives, 13, 141-154.

Stone, J. (2013). "Unlucky" Gettier cases. Pacific Philosophical Quarterly, 94(3), 421-430.

Williamson, T. (2000). Knowledge and its limits. Oxford University Press.

Williamson, T. (2009). Reply to John Hawthorne and Maria Lasonen-Aarnio. In P. Greenough \& D. Pritchard (Eds.), Williamson on Knowledge (pp. 313-329). Oxford University Press.

Zalabardo, J. L. (2017). Safety, sensitivity and differential support. Synthese, 197(12), 5379-5388.

Zhao, H. (2019). Better virtuous than safe. Synthese. https://doi.org/10.1007/s11229-019-02501-5

Publisher's Note Springer Nature remains neutral with regard to jurisdictional claims in published maps and institutional affiliations. 